\title{
"VOZES DO BOLSA FAMÍLIA: AUTONOMIA, DINHEIRO E CIDADANIA" ENTREVISTA REALIZADA COM ALESSANDRO PINZANI*
}

“VOICES OF THE BOLSA FAMÍLIA: AUTONOMY, MONEY AND CITIZENSHIP”

INTERVIEW WITH ALESSANDRO PINZANI

ENTREVISTA CON ALESSANDRO PINZANI SOBRE EL LIBRO “VOZES DO BOLSA FAMÍLIA: AUTONOMIA, DINHEIRO E CIDADANIA".

Os Editores

REVISTA PEDAGÓGICA

Revista do Programa de Pós-graduação em Educação da Unochapecó | ISSN 1984-1566 Universidade Comunitária da Região de Chapecó | Chapecó-SC, Brasil Como referenciar este artigo: SILVA, Maurício Roberdo da. Vozes do Bolsa Família: autonomia, dinheiro e cidadania- Entrevista realizada com Alessandro Pinzani. Revista Pedagógica, Chapeó, v.16, n.32, p. 207-216, jan./jul. 2014. 
* Entrevista realizada em 5 de setembro de 2014, a partir do livro de Walquiria Leão Rego e Alessandro Pinzani, Vozes da Bolsa Família: autonomia, dinheiro e cidadania. São Paulo: UNESP, 2013.

** Professor do Programa de Pós-graduação em Educação Física da Universidade Federal de Santa Catarina (UFSC) de 2002 a 2008. Professor aposentado da UFSC. Atualmente é professor no Programa de Pós-graduação em Educação, da Universidade Comunitária da Região de Chapecó, especificamente, na linha de pesquisa Desigualdades sociais, diversidades socioculturais e práticas educativas.
2 Psicóloga. Mestranda pelo Pós-Graduação em Educação da UNOCHAPECÓ. Bolsista CAPES. E-mail: anakb@unochapeco.edu.br
A Revista Pedagógica, em uma de suas seções intitulada ENTREVISTAS, procura trazer para reflexão, questões polêmicas, complexas e multidimensionais, relativas à área da Educação e áreas afins. A ideia é contribuir para que os leitores da academia e das escolas, reflitam acerca de paradoxos/contradições inerentes às diversas facetas das problemáticas educacionais que, terminam por reverberar nos processos e práticas educativas do cotidiano escolar e não escolar. Nossa intenção é problematizar questões, cujas respostas ainda carecem de superação das generalizações e superficialidade, advindas, sobretudo, da adesão imediata de parte da comunidade acadêmica, que se manifesta a partir das representações sociais de um certo tipo de "senso comum" forjado pelas mídias e, as vezes, pela desinformação e ausência de pesquisas críticas no âmbito acadêmico.

Diante disso e considerando a emergência de aprofundamento sobre os limites e possibilidades das políticas públicas e sociais, especificamente, do Programa de Transferência de Renda, Bolsa Família, a Revista lançou algumas perguntas, motivadas pelas ideias contidas no relevante livro "Vozes da Bolsa Família: Autonomia, dinheiro e cidadania". O livro aborda uma gama de questões polêmicas e esclarecedoras sobre o Programa Bolsa Família, cujos conteúdos são frutos de um exaustivo trabalho de pesquisa qualitativa realizada ao longo de cinco anos (de 2006 a 2011) com mulheres de diversos estados brasileiros.

Editores: Quais os motivos que levaram vocês a produzir a pesquisa pelo Brasil afora, tendo como mote "vozes" de mulheres empobrecidas e beneficiárias do Programa Bolsa Família (PBF), principalmente, aquelas que residem nas regiões consideradas "mais desassistidas" do país, tais como, o sertão de Alagoas, zona litorânea de Alagoas, vale doJ equitinhonha (MG), interior do Piaú, interior do Maranhão, as periferias de São Luís (MA) e de Recife (PE)?

Alessandro Pinzani: Quando iniciamos nossa pesquisa, a maioria dos estudos sobre o $\mathrm{PBF}$ se concentravam sobre os aspectos econômicos ou resultavam da aplicação de questionários. Ora, élegítimo eimportante realizar pesquisas deste tipo, servindo-se de uma metodologia quantitativa, mas o que nos interessava era o efeito do PBF sobre a subjetividade das pessoas, sobre sua maneira de ver-se em sua relação com o mundo externo, com sua comunidade e com a sociedade brasileira. Isso não é algo que possa ser estudado com questionários, mas requer uma pesquisa realizada com uma metodologia qualitativa, através de entrevistas abertas, com um roteiro de perguntas.

Editores: Por que elegeram as mulheres dessas regiões como sujeitos principais da pesquisa? 


\begin{abstract}
Alessandro Pinzani: Trata-se de regiões tradicionalmente entre as mais pobres e mais negligenciadas pelos governos (em todos os níveis: federal, estadual e até municipal) ao longo da história brasileira. Além disso, escolhemos como sujeitos da pesquisa os pobres deáreas rurais, pois eles se deparam com problemas diferentes daqueles enfrentados pelos pobres de áreas urbanas. Seu isolamento geográfico acentua muitos aspectos característicos da pobreza, como descrevemos no livro, particularmente no quarto capítulo. Ao isolamento geográfico corresponde um isolamento político, social, cultural e muitas vezes até humano.
\end{abstract}

Editores: Quais as principais representações sociais dos estudiosos e acadêmicos sobre os programas de distribuição de renda em geral e, em particular, sobre o PBF, uma vez que há aqueles que negam, radicalmente, seu papel positivo na superação da pobreza, argumentando que se trata, unicamente, de um programa de inclusão social de caráter precário, eleitoreiro, paternalista, assistencialista, clientelista e filantrópico; há aqueles que afirmam seu papel positivo para a construção da cidadania e superação da miséria; e há aqueles ainda que, apesar de fazer críticas, veem o PBF como irreversível e com muitas possibilidades de continuidade e superação?

Alessandro Pinzani: O PBF é aquele que na literatura especializada é chamado de CCT Program, ou seja, um programa de transferência condicional de renda. É um tipo específico de programa social que, normalmente, é acompanhado por outros programas sociais. Isso é o caso também do PBF, já que o Ministério de Desenvolvimento Social e Combate à Fome (MDS) mantém quase sessenta programas sociais além dele. Este aspecto é frequentemente esquecido nos debates políticos e até acadêmicos, mas é fundamental. Não há como combater a pobreza somente por meio de programas CCT. Em certo sentido, é um programa emergencial, pois tem como objeto a miséria extrema e como público-alvo pessoas que têm dificuldade de garantir a sobrevivência de suas famílias e de planejar minimamente sua vida. É um programa governamental, não um direito amparado na constituição (embora exista no Brasil uma lei que prevê o pagamento de uma renda básica universal - lei que ainda espera sua implementação e cuja existência muitos desconhecem). Por isso, o PBF torna-se regularmente objeto dos debates eleitorais, pois uma mudança de governo poderia significar a interrupção do programa ou uma profunda transformação do mesmo.

Sobre a acusação de que seria um programa eleitoreiro, gostaríamos de perguntar qual programa governamental pode ser isento de tal acusação. O plano industrial e econômico que todo governo tem não seria uma maneira de tentar ganhar o voto dos empresários ou dos trabalhadores? As isenções e os incentivos fiscais para as empresas e 
para os consumidores, não o seriam? Por que élícito para a classe média votar pelos candidatos que melhor garantem seu interesse, sem que ninguém se escandalize, e quando os pobres fazem isso se fala em compra e venda de votos?

O PBF cria dependência? No máximo, poderíamos dizer que substitui uma dependência (a da falta de condições materiais) por outra dependência (a da ajuda do governo). Mas, de novo, ninguém utilizaria esta linguagem para as outras classes e os outros serviços garantidos pelo governo. Os cidadãos acham óbvio que o governo ofereça as condições para ver garantido seu direito de ir e vir, por exemplo. Ora, o direito de não passar fome e de viver uma vida minimamente digna não é um direito pelo menos tão importante? O fato de um governo disponibilizar os instrumentos para isso, não significa em si a criação de uma relação de dependência. Gostaríamos também de lembrar que cada ano milhares de famílias saem voluntariamente do PBF por ter conseguido alcançar uma renda superior àquela que permite o acesso ao programa.

Editores: Quais as representações do senso comum a respeito dos subsídios do PBF, ou seja, dos sujeitos pertencentes às diversas classes sociais (pobres, classe média e elites)?

Alessandro Pinzani: O argumento que se ouve frequentemente nas discussões sobre o PBF (inclusive nos tantos debates dos quais participamos) é de que é melhor ensinar às pessoas a pescar, em vez de dar-lhes um peixe, como diz um provérbio chinês. O problema é que no sertão não tem peixe, para ficar nesta metáfora. Em outras palavras: estamos falando de uma pobreza estrutural, que não é o resultado contingente de uma crise econômica, como no caso da pobreza que seguiu a crise de 1929 nos EUA, descrita por tantos livros e filmes (por ex. no romance As vinhas da ira, de Steinbeck e no homônimo filme de J ohn Ford). A pobreza nas regiões visitadas por nós ou nas favelas e nos bairros urbanos pobres é consequência de uma secular falta de compromisso social e político por parte dos governos e das elites. Em alguns casos, é quase impossível imaginar que a situação possa ser resolvida sem maciços investimentos públicos (como aconteceu justamente nos EUA dos anos Trinta com a política do New Deal). Consideremos, por exemplo, regiões como o Vale do J equitinhonha: é inimaginável que empresas privadas criem vagas de trabalho em uma região tão distante do mar e dos portos, com estradas em péssimas condições etc. Isso sem contar a falta de mão de obra qualificada. Por isso, de nada adiantaria o governo federal (já que os estaduais o os municipais em geral pouco fazem para melhorar o nível de educação pública, como fica claro aqui em Santa Catarina, por exemplo) abrir Institutos Técnicos Federais naquelas regiões, pois isso faria com que os alunos egressos sejam obrigados 
a se mudar para as longínquas cidades ou para outros estados, sem mudar nada na região. Seria necessário criar trabalho naquelas regiões e, mais uma vez, a iniciativa privada nunca vai conseguir isso sozinha.

Lembramos que todas as mulheres entrevistadas por nós afirmaram que o PBF é uma ajuda e que para resolver sua situação prefeririam um trabalho regular e com carteira assinada. Isso desmente o preconceito de que os participantes do PBF não querem trabalhar e preferem viver da bolsa. O valor médio da bolsa é R\$ 140, chegando a um máximo de $\mathrm{R} \$ 240$. Ninguém consegue sobreviver com isso, nem sequer nas regiões mais pobres. Todos os participantes do programa trabalham, ou na agricultura de subsistência (na roça), ou fazendo bicos pelos quais são mal pagos. O outro lado da pobreza é a exploração por parte da classe média ou dos latifundiários que se aproveitam do desespero dessas pessoas para pagar salários indignos por trabalhos duros: dez reais por oito horas de trabalho na roça, ou cento e cinquenta reais mensais para trabalhar como empregada doméstica seis dias por semana, só para relatar alguns exemplos que ouvimos.

Editores: Por que há tantos preconceitos contra o $\mathrm{PBF}$, tanto dos partidos políticos de "direita" quanto dos de "esquerda"?

Alessandro Pinzani: No caso da "direita", às vezes se trata de defender os privilégios de quem explora o desespero dos pobres, como acabamos derelatar. Em geral, defende-se uma visão que tende a naturalizar a pobreza (como se ela fosse um fato natural que obedece a leis imutáveis e não a consequência de ações humanas e de arranjos sociais que, pelo contrário, poderiam ser transformados) e a responsabilizar o pobre pela sua situação. É uma forma de racionalização a posteriori de um estado de coisas contingentes e uma maneira para sentir-se melhor que os outros. A pessoa que tem dinheiro e uma boa posição social gosta de atribuir unicamente a si mesma o mérito disso; especularmente, ela atribui ao pobre sua situação de pobreza. Ninguém se pergunta: o que teria acontecido comigo se tivesse nascido em uma família pobre lá no vale do J equitinhonha em vez de nascer de uma família de classe média em Florianópolis ou em São Paulo? A ideologia do mérito ofusca o fato que na chamada "corrida da vida" não saímos todos das mesmas condições de partida e que, portanto, o que alcançamos nela não depende somente de nós, mas também de circunstâncias sobre as quais não temos controle.

Certa esquerda critica o PBF por criar indivíduos acomodados e dependentes do governo. Ouvimos até o argumento de que o PBF "atrasaria a revolução". Ora, cabe lembrar que a pobreza no Brasil é um fenômeno secular e que em momento nenhum ela levou a uma revolução, limitando-se a trazer consigo sofrimento para milhões de 
pessoas. Uma revolução na forma de um levante popular que inclua os mais pobres precisaria de indivíduos com um mínimo de consciência política, mas as pessoas que entrevistamos relataram quase todas que antes de receber o PBF elas se sentiam menos que "gente"; algumas se compararam a "bichos" que saem cada dia buscando comida, pois esta era literalmente a realidade delas. Mas certa esquerda não se preocupa muito em ver quais eram as condições de vida nas quais estas pessoas se encontravam concretamente. Precisa de muito cinismo para defender a visão do "quanto pior, melhor" implícita na acusação de que o PBF atrasa a revolução.

Editores: Em que medida as críticas (limites) ao PBF são legítimas e quais são os seus avanços efetivos?

Alessandro Pinzani: O PBF não representa, não pode representar e não quer representar uma solução definitiva ao problema da pobreza. Uma vez que aceitamos isso, muitas das críticas que lhe são feitas se relativizam. É um programa que visa tirar da pobreza extrema uma parcela relevante da população (55 milhões, ou seja, mais de um quarto dos brasileiros) e que acompanha outros sessenta programas. Criticá-lo porque não resolve de vez a pobreza, significa não ter entendido qual é o objetivo do programa.

Há, contudo, vários limites. O primeiro é o fato, acima mencionado, de ser um programa governamental e, portanto, de depender de situações políticas contingentes: se mudar o governo, pode mudar profundamente o programa. Em segundo lugar, o valor da bolsa é muito baixo. Há quem acha que não é assim. Lembramos que os gastos com o PBF são inferiores ao 0,5\% do PIB e que por cada real investido nele, há um retorno de quase $\mathrm{R} \$ 1,75$ em termos de PIB. Houve vários reajustes nos últimos anos, mas ainda é um valor baixo. Em terceiro lugar, há problemas na implementação do programa na esfera municipal. Há um problema de capacitação de gestores e de vontade política dos administradores locais, particularmente dos prefeitos. O MDS está organizando cursos de capacitação para gestores, mas se os políticos locais fazem corpo mole, as dificuldades permanecem. Em quarto lugar, há problemas na atitude dos funcionários públicos que, em geral, se ocupam da implementação de políticas sociais. No caso do PBF, isso se manifesta na atitude de agentes de saúde, funcionários do Centro de Referência de Assistência Social (CRAS) e do serviço social, professores etc., que tratam de maneira humilhante os participantes do programa. As entrevistadas se queixavam bastante de funcionários que enviam cartas em estilo burocrático para mulheres analfabetas ou se recusam de explicar de maneira clara os procedimentos de cadastramento, ou dos gestores do programa nas escolas. Uma série de entrevistas com gestores escolares no Nordeste, realizada por algumas colegas, revelou um nível de precon- 
ceito espantoso contra as crianças pobres. O Ministério da Educação (MEC) está começando a oferecer cursos de especialização a distância para resolver este problema, mas ainda há dificuldades ligadas à persistência de fortes preconceitos contra os pobres inclusive entre os que deveriam conhecer melhor sua situação e trabalhar para resolvê-la.

Em relação aos efeitos positivos, além daqueles econômicos mencionados acima (lembramos que alguns dias atrás a ONU tirou o Brasil do mapa mundial da fome), preferimos remeter ao nosso livro, no qual registramos indícios de que o PBF está abrindo fendas de liberdade e iniciando processos de autonomização dos participantes. A presença de uma renda monetária regular abre espaços de autonomia para as mulheres entrevistadas, que passam a poder planificar minimamente a vida delas e de sua família. Além disso, a grande maioria delas relata que pela primeira vez percebem que o Estado está se interessando pelos seus problemas e isso faz com que passem a ter uma percepção de si como cidadãs, como membros da comunidade política brasileira.

Editores: Frei Betto, no âmbito do Ciclo de Palestras e Conferências, sob o tema Reflexões sobre os projetos e programas de inclusão social no âmbito das políticas públicas e sociais, realizado pelo PARFOR/Unochapecó e do Café Filosófico (PPGE/ Unochapecó/PARFOR), em dezembro de 2013, alegou que saiu do governo Lula, após dois anos, em razão da incompatibilidade de concepções de políticas de transferência de renda, nomeadamente, a opção do governo pelo $\mathrm{PBF}$, ao invés da manutenção e continuidade do "Programa Fome Zero" com seus sessenta itens que levavam à autonomia dos sujeitos e não ao atrelamento aos ditames das políticas sociais provisórias e precárias. O que podem dizer sobre essa questão?

Alessandro Pinzani: Não conhecemos nos pormenores as críticas de Frei Betto. Repetimos que o PBF é um entre sessenta programas sociais do MDS e, por isso, não deveria ser considerado isoladamente. Além disso, prevê a distribuição de renda, não de comida - e isso nos parece um passo a frente relativamente ao Fome Zero. Um programa que distribui comida é assistencialista (fora os casos de catástrofes naturais etc.) e paternalista, pois impõe a seus beneficiários certas escolhas tomadas por outros atores (por exemplo: o governo decide o que eles irão comer, quanto irão comer etc.). Um programa que distribui dinheiro deixa as pessoas livres para escolher como usar os recursos que lhes são disponibilizados.

Editores: Quais as relações entre o PBF e os demais programas sociais do governo federal, a saber: PAC; Minha Casa, Minha Vida; Mais Médicos; Pronatec; Brasil Sem Miséria? 
Alessandro Pinzani: Todos são vinculados direta ou indiretamente ao MDS e pretendem combater as diferentes facetas da miséria. A falta de assistência médica é uma delas, por exemplo, e não pode ser resolvida através da transferência de renda, se não houver um programa que garanta a presença de médicos em áreas pobres como o vale doJ equitinhonha (mas o Mais Médicos é ativo inclusive em bairros pobres de Florianópolis, nos quais os médicos - formados em sua maioria em universidades públicas e gratuitas - se recusavam atender).

Editores:Há um anúncio por parte do governo atual, alegando que o PBF reduziu significativamente a "miséria extrema". Nesse sentido, o que a pesquisa realizada por vocês aponta acerca dessa questão?

Alessandro Pinzani: Esta pergunta foi respondida acima. Dequalquer maneira, não é disso que nos ocupamos no livro. Dados relativos ao impacto econômico do PBF se encontram antes nas publicações do IPEA e de outros institutos de pesquisa econômica.

Editores: Em que medida, o recebimento do benefício, muitas vezes, a primeira experiência de renda regular das famílias, tem modificado, efetivamente, a vida das beneficiárias e de suas famílias, evidenciando, assim, os efeitos políticos, morais, primários e secundários do PBF?

\begin{abstract}
Alessandro Pinzani: Bom, para responder a essa pergunta deveríamos fazer em poucas linhas um resumo do livro inteiro, e isso é complicado. Em síntese, podemos afirmar que esta experiência abriu para as participantes novas perspectivas, anteriormente inimagináveis. Como dissemos anteriormente, a incerteza do dia a dia, que muitas vezes significava inclusive incerteza sobre a disponibilidade de comida, foi substituída pela certeza dessa renda, por mínima que seja (por "este dinheirinho", como diziam algumas das entrevistadas). Mas, principalmente, a renda regular lhes trouxe crédito em suas comunidades, particularmente entre os comerciantes locais. Para quem nunca passou pela experiência humilhante de ser afastado de uma loja por ser pobre ou pelo desânimo de não poder comprar nem umas balinhas para seu filho, isso pode parecer um aspecto secundário, mas muitas das entrevistadas salientaram a importância desse fato para sua vida. Acostumadas a viver em uma sociedade extremamente materialista, onde "para tudo precisa dinheiro", como disse uma delas, elas passaram a ser consideradas com outro olhar pelos demais membros da comunidade, uma vez que começaram a receber a bolsa. O preconceito contra o pobre é tão forte que acaba sendo interiorizado pelos mesmos pobres, que passam a se ver pelos olhos dos comerciantes. Podemos considerar horrível isso, mas é parte de nossa realidade social,
\end{abstract}


inclusive daquela da classe média (o cartão de crédito não passa de uma maneira de ver reconhecida por uma instituição financeira a própria confiabilidade como pagador e, afinal, como pessoa, embora poucas vezes nos lembremos disso, quando o sacamos para fechar uma compra).

Ao mesmo tempo, a renda regular garantiu às participantes do PBF um mínimo de capacidade de planejar a vida delas e de suas famílias, e isso é a base para começar a falar em autonomia no sentido mais amplo do termo, junto à liberação das carências mais tacanhas e à satisfação das exigências mais básicas como comida etc. É como se alcançassem um novo patamar de desenvolvimento humano, a partir do qual podem começar a considerar sua situação com um olhar diferente. Algumas delas encontraram na segurança da renda regular inclusive o estímulo para se separar de maridos abusivos ou para deixar suas famílias opressoras, embora se trate ainda de casos isolados (lembro que elas não vivem somente da Bolsa, mas trabalham, ainda que de maneira irregular e com salários exploradores).

Além disso, o PBF quebrou em muitos lugares com o poder político dos coronéis locais, que muitas vezes conseguiam comprar o voto em troca de um pouco de dinheiro ou de comida. Isso mudou, como testemunham as verdadeiras revoluções políticas em estados como Bahia, Piauí e agora Maranhão, onde famílias e grupos que mantinham o poder há décadas acabaram derrotados, mas também em muitos municípios (e nem sempre em prol do PT ou de seus aliados). Muitas das entrevistadas apontaram para o fato de que pela primeira vez sentiram que o Estado estava se interessando nelas. Por isso, apesar de muitas delas não gostarem de votar nas eleições locais e de considerar que os políticos são ladrões, todas afirmaram que no caso das eleições presidenciais seu voto conta, uma vez que perceberam que votando por certo governo algo mudou na vida delas. Em suma, estão apreendendo a importância do voto como instrumento de cidadania e de expressão dos seus interesses legítimos (ao menos tão legítimos quanto os dos eleitores de classe média que votam por candidatos que prometem isenções fiscais, abolição de impostos sobre compras no exterior etc.).

Editores: Como as mulheres-mães se posicionaram sobre as chamadas condicionalidades para garantir o acesso e permanência das crianças na escola?

Alessandro Pinzani: Em sua maioria acham ótimo que as crianças possam permanecer na escola. Muitas entre elas foram retiradas da escola em sua infância para ajudar no trabalho doméstico ou até para trabalhar na roça. Todas veem na educação dos filhos uma possibilidade para estes saírem da miséria que elas acabaram considerando seu destino inevitável. Ouvimos relatos de problemas liga- 
dos à condicionalidade da permanência, mas, como dissemos antes, a maioria deles dependia principalmente da má vontade ou de preconceito dos gestores do programa nas escolas. O livro contém alguns relatos significativos, deste ponto de vista. É claro que a questão das condicionalidades pode criar uma situação de estresse para os participantes do programa. Por outro lado, as duas condicionalidades têm uma dupla função: uma prática e imediata é a de manter as crianças nas escolas e de contribuir para erradicar doenças como a poliomielite etc.; a outra, mais indireta, é a de suscitar nas participantes a impressão de que elas recebem o dinheiro enquanto cidadãs que possuem, além de seus direitos, deveres para com a comunidade política. Condicionalidades deste tipo podem ser vistas a partir de uma perspectiva republicana, neste sentido.

Editores: Que críticas poderiam ser realizadas às perguntas formuladas e o que ficou em suspenso para futuras pesquisas neste campo de investigação?

Alessandro Pinzani: Há ainda muito a ser investigado. Em primeiro lugar, dever-se-ia pesquisar se os avanços registrados pela nossa pesquisa se confirmam e se é possível falar abertamente em um processo de autonomização desencadeado pelo PBF. Isso vai requerer tempo e paciência dos pesquisadores (nossa pesquisa, por exemplo, exigiu cinco anos de entrevistas demoradas, voltando mais vezes no mesmo lugar, quando possível). Em segundo lugar, dever-se-ia averiguar o impacto das condicionalidades na situação psicológica das participantes - e há já pesquisas que estão sendo realizadas neste sentido. Finalmente, a questão do despreparo e dos preconceitos dos gestores e dos outros funcionários envolvidos na implementação do PBF deveria ser objeto de estudos específicos que registrem se houve ou não mudanças de atitude.

* Entrevista realizada em 5 de setembro de 2014. 